https://doi.org/10.15690/vsp.v20i6.2356
И.А. Беляева ${ }^{1,2,3}$, Т.В. Турти ${ }^{1,2,4}$, Е.П. Бомбардирова ${ }^{1}$, П.Е. Садчиков ${ }^{1,2}$, А.Ю. Нагонов ${ }^{1,2}$
${ }^{1}$ НИИ педиатрии и охраны здоровья детей ЦКБ РАН, Москва, Российская Федерация
2 Российский национальный исследовательский медицинский университет им. Н.И. Пирогова, Москва,
Российская Федерация
3 Морозовская детская городская клиническая больница, Москва, Российская Федерация
4 НИИ организации здравоохранения и медицинского менеджмента, Москва, Российская Федерация

\section{Стратегии научно-практического поиска: существует ли связь между формированием оси "кишечник - мозг" и характеристиками сна младенцев?}

Контактная информация:

Беляева Ирина Анатольевна, доктор медицинских наук, профессор РАН, профессор кафедры факультетской педиатрии педиатрического факультета РНИМУ им. Н.И. Пирогова, главный научный сотрудник НИИ педиатрии и охраны здоровья детей ЦКБ РАН, врач-неонатолог высшей квалификационной категории Морозовской детской городской клинической больницы

Адрес: 119333, Москва, ул. Фотиевой, д. 10, стр. 1, тел.: +7 (499) 137-01-97, e-mail: irinaneo@mail.ru

Статья поступила: 22.10.2021, принята к печати: 17.12 .2021

В обзоре приведен анализ современных публикаций по проблеме взаимосвязи формирования кишечной микробиоты ребенка с созреванием паттернов нейрофизиологической деятельности на примере становления возрастной структуры сна. Показана значимость этапного созревания кишечной микробиоты в свете концепции оси "Головной мозг - кишечный микробиом" (brain - gut microbiom axis); описаны механизмы и медиаторы, задействованные в формировании этой оси и обоснована ее онтогенетическая значимость. Представлены основные этапы становления функции сна у ребенка как важного компонента общего созревания психики во взаимосвязи с факторами окружающей среды и установками семьи, а также рекомендации по продолжительности периодов сна; оценка характеристик засыпания и структуры сна. Показаны прямые и обратные связи количественных и качественных параметров микробиоты с эффективностью сна. Выявлена положительная корреляция между консолидированностью сна, количеством и разнообразием видов Bacteroidetes в кишечной микробиоте, а также составом бактериальных метаболитов. Наличие указанных связей является теоретическим обоснованием для разработки методов патогенетической коррекции нарушений как микробиоты, так и сна.

Ключевые слова: сон, диета, питание, режим сна, младенец, развитие, кишечная микробиота

Для цитирования: Беляева И.А., Турти Т.В., Бомбардирова Е.П., Садчиков П.Е., Нагонов А.Ю. Стратегии научно-практического поиска: существует ли связь между формированием оси "кишечник - мозг" и характеристиками сна младенцев? Вопросы современной педиатрии. 2021;20(6):499-505. doi: 10.15690/vsp.v20i6.2356

Irina A. Belyaeva ${ }^{1,2,3}$, Tatiana V. Turti ${ }^{1,2,4}$, Elena P. Bombardirova ${ }^{1}$, Pavel E. Sadchikovi, ${ }^{1, A l e x a n d e r ~ Y u . ~ N a g o n o v ~}{ }^{1,2}$

${ }^{1}$ Research Institute of Pediatrics and Children's Health in “Central Clinical Hospital of the Russian Academy of Sciences”, Moscow, Russian Federation

2 Pirogov Russian National Research Medical University, Moscow, Russian Federation

${ }^{3}$ Morozovskaya Children's City Hospital, Moscow, Russian Federation

${ }^{4}$ Research Institute for Healthcare Organization and Medical Management, Moscow, Russian Federation

\title{
Strategies for Scientific and Practicall Search: is There Any Correlation Between the Development of the Gut-Brain Axis and the Sleep Characteristics in Infants?
}

The review provides the analysis of modern publications on the topic of correlation between development of intestinal microbiota and maturation of neurophysiological activity patterns (on the example of sleep age structure development). The importance of the stage maturation of intestinal microbiota in the concept of the gut-brain axis is presented. Mechanisms and mediators involved in this axis are described, and its ontogenetic significance is justified. The main stages of sleep function development in a child as an important component of the general mental health maturation in relation to environmental factors and family features are presented. Recommendations on sleep periods duration and estimation of sleep onset and sleep structure are also given. Direct and reverse correlations of quantitative and qualitative microbiota parameters with sleep efficiency are shown. Positive correlation was identified between sleep consolidation, number and diversity of Bacteroidetes species in intestinal microbiota, and composition of bacterial metabolites. The presence of such correlations is theoretical justification for further development of methods of pathogenetic therapy of both microbiota and sleep disorders.

Keywords: sleep, diet, nutrition, sleeping schedule, infant, development, intestinal microbiota

For citation: Belyaeva Irina A., Turti Tatiana V., Bombardirova Elena P., Sadchikov Pavel E., Nagonov Alexander Yu. Strategies for Scientific and Practicall Search: is There Any Correlation Between the Development of the Gut-Brain Axis and the Sleep Characteristics in Infants? Voprosy sovremennoi pediatrii - Current Pediatrics. 2021;20(6S):499-505. (In Russ). doi: 10.15690/vsp.v20i6.2356 


\section{ВВЕДЕНИЕ. СТАНОВЛЕНИЕ КИШЕЧНОЙ МИКРОБИОТЫ МЛАДЕНЦА: ОСНОВНЫЕ ВЛИЯЮЩИЕ ФАКТОРЫ}

Развитие - это огромное число расходящихся направлений.

А. Бергсон

В последние десятилетия в рамках концепции «первых 1000 дней" широко изучается значимость микробиома человека, в особенности - связь ранних этапов онтогенеза микробиоты кишечника младенца с отсроченными нарушениями здоровья [1, 2]. Количественное и качественное своеобразие (индивидуальный "портрет" микробиома) формируется на протяжении раннего детства, причем на него влияют и факторы наследственности, но в первую очередь - многочисленные факторы внешней среды. Существуют противоречивые гипотезы о времени начала колонизации здорового ребенка микробами-симбионтами: концепция внутриутробной колонизации даже при неповрежденном плодном пузыре и концепция "рождения микробиоты вместе с ребенком" [3]. Одним из важнейших факторов, определяющих состав и разнообразие стартовой микробиоты новорожденного, признан способ родоразрешения: установлено, что при вагинальных родах младенец контаминируется сапрофитной флорой матери, в которой преобладают лактобациллы (у здоровых женщин); этот род микроорганизмов создает благоприятные условия для этапного включения в состав симбионтов облигатных анаэробов [4]. Впоследствии основным онтогенетическим фактором в формировании микробиоты становится характер вскармливания. Наиболее адекватные условия формирования здоровой микробиоты создаются при исключительно грудном вскармливании за счет уникальных биологически активных субстанций грудного молока ( $\alpha$-лактальбумин, олигосахариды, длинноцепочечные полиненасыщенные жирные кислоты (ДЦ ПНЖК), лактоферрин и др.), которые способствуют росту симбионтных микроорганизмов $[5,6]$. Проспективные наблюдения позволили установить достоверные связи нарушений формирования микробиоты кишечника у младенцев не только с частой инфекционной патологией, опосредованной изменениями в иммунной системе, но и с отсроченными эндокринными и метаболическими нарушениями, а также с повышенным риском аллергических реакций [7]. Сформулированы концепции биологических осей "микробиом - иммунитет", "Микробиом - головной мозг" [8, 9]. Признание функционирования оси "кишечная микробиота - головной мозг" делает актуальным изучение взаимосвязей микробиоты с нейропсихическими функциями, в том числе с когнитивной сферой.

\section{ОСЬ «ГОЛОВНОЙ МОзГ - КИШЕЧНАЯ МИКРОБИОТА"}

Есть тонкие властительные связи...

В. Брюсов. Сонет к форме

В работах последних лет сформулировано понятие ось "Головной мозг - кишечник - микробиом" (BGMA: brain - gut - microbiome axis) [9], поскольку доказано взаимовлияние структуры кишечной микробиоты у взрослых субъектов и особенностей их психического состояния [10]. Не только при патологиях желудочно-кишечного тракта нарушается психоэмоциональный статус [11], но нарушения состава кишечной микробиоты выявляются при нервно-психической патологии, например при расстройствах аутистического спектра [12]. Предполагаемые механизмы, обеспечивающие эту связь, - воздействие микробов на иммунные и гормональные реакции, проницаемость кишечного эпителия и гематоэнцефалический барьер [13]. Важный медиатор микробного воздействия - метаболиты, влияющие через посредство иммунных реакций: так, короткоцепочечные жирные кислоты (КЦЖК) могут тормозить выброс провоспалительных цитокинов; индол стимулирует секрецию интерлейкина IL-22 и антимикробных пептидов [14]; некоторые микробные метаболиты связаны с дифференцировкой В-клеток [15].

Таким образом, формирующаяся кишечная микробиота младенца может оказывать влияние на его последующее психическое и физическое здоровье различными путями, в том числе через ось “мозг - кишечник - микробиота" [16]. Кишечные бактерии могут влиять на нервные [17], гормональные [18] и иммунные реакции [13], на проницаемость слизистой оболочки кишечника [19] и гематоэнцефалического барьера [20].

Роль оси "мозг - кишечник - микробиота" в развитии нарушений сна пока еще малоизучена, особенно у детей в процессе как формирования физиологических паттернов сна, так и нарушения созревания ритма "Сон бодрствование».

\section{СОН МЛАДЕНЦА КАК РАЗВИВАЮЩАЯ ФУНКЦИЯ. BОЗРАСТНЫЕ ОСОБЕННОСТИ СНА. ЧТО ОБЕСПЕЧИВАЕТ ЗДОРОВЫЙ СОН И ЧТО EГO НАРУШАET?}

Сон - это лучшее лекарство от бодрствующих бед.

Мигель де Сервантес

Последние научные данные указывают, что сон - это физиологическое состояние, которое неразрывно связано со многими функциональными системами организма. Короткую продолжительность сна, частые ночные пробуждения исследователи соотносят с ухудшением показателей познавательного и поведенческого развития. В обзоре десяти исследований детского сна и нервнопсихического развития была выявлена положительная связь между сном, памятью, речью, исполнительной функцией и общим когнитивным развитием у здоровых младенцев [21]. В другом исследовании с участием 590 здоровых детей в возрасте 2-11 мес и 512 детей в возрасте 12-30 мес сделан вывод, что частые ночные пробуждения связаны с плохими когнитивными функциями [22]. Современные исследования показывают, что функциональная зрелость здоровых младенцев выражается в том числе в показателях количества и структуры сна (общая продолжительность сна, продолжительность фаз спокойного и активного сна, процент сна в ночное время). Эти важные характеристики сна нужно оценивать в контексте адаптации развивающегося ребенка к конкретным требованиям и возможностям культурально-структурированной среды развития - организация сна младенцев отличается в разных странах [23]. Однако еще недостаточно данных о том, сколько сна (консолидированного или нет) действительно требуется для здорового развития ребенка. Общая продолжительность 
сна младенцев за сутки имеет сильные индивидуальные различия, но различия в продолжительности сна также зависят от принадлежности к различным культурным традициям. Тем не менее, имеется общее понимание необходимости создания программ раннего вмешательства, способствующих созреванию сна младенцев. Программы обучения родителей внимательному отношению к младенческому сну, направленные на чуткое реагирование на сигналы младенца, а также на сохранение дотации грудного молока во втором полугодии жизни после введения прикорма, способствуют созреванию циркадианных ритмов сна-бодрствования и укрепляют семейные взаимоотношения [24].

Нарушения структуры сна (частые пробуждения, затрудненное засыпание) могут приводить к отсроченным патологическим состояниям, связанным с метаболическими и иммунными расстройствами [25]. Помимо этого, повышается риск невротических и когнитивных нарушений [26]. По данным зарубежных публикаций, до 15-25\% детей имеют беспокойный сон на протяжении первого года жизни [27, 28].

Режим сна, количество часов сна, продолжительность периодов дневного и ночного сна изменяются в течение первого года жизни ребенка. В первые 3 мес продолжительность сна варьирует и составляет от 17 до 14 ч в сутки. Эти различия значимо связаны с характером вскармливания. При грудном вскармливании существует потребность в более частом кормлении по сравнению с искусственным вскармливанием. В период от 3 до 6 мес общая продолжительность сна в сутки сокращается до 12-15 ч, это связано с удлинением интервалов между кормлениями. Примерно в этом возрасте большинство здоровых младенцев начинают спать всю ночь, хотя из этого правила имеются исключения [29]. Важным условием нормального развития является консолидация (непрерывность без пробуждений) ночного сна. Наиболее активные процессы организации и регуляции детского сна происходят в первые 4 мес жизни. Исследователи выявили, что наиболее приемлемым с точки зрения развития и социальной значимости периодом суток для сна является время с 22:00 до 06:00. В 5 мес жизни более половины младенцев спят одновременно со своими родителями [30].

Данные Национального фонда сна (США) показывают широкий диапазон общей продолжительности сна за 244 для младенцев и детей раннего возраста (табл. 1) [31].

В первые месяцы жизни младенцы переживают период самого быстрого роста вне зависимости от характера вскармливания, что обосновывает потребность в частом кормлении. Чтобы проиллюстрировать, как быстро растет мозг, ученые Калифорнийского университета сканировали мозг 87 здоровых младенцев от рождения до 3 мес. Самые быстрые изменения зарегистрированы сразу после рождения - объем мозга новорожденного увеличивался в среднем на 1\% в день. K концу 90-дневного периода жизни этот показатель снизился до 0,4\% в день [32].

По данным M. Walker (2017), младенцы и маленькие дети демонстрируют "полифазный сон", это означает, что в течение суток существует множество периодов сна, «перемежающихся многочисленными пробуждениями, нередко с криком" [33]. Как считают ученые, только к 12 мес жизни супрахиазматическое ядро мозга начинает осуществлять контроль над регуляцией физиологических циркадианных ритмов, т.е. к 1 году жизни большинство младенцев могут "спать всю ночь". Однако в исследовании М.H. Pennestri и соавт. (2018) было зарегистрировано, что к 12 мес 28\% младенцев еще не спали 6 ч по ночам, а 43\% не спали без пробуждений 8 ч [34]. Обзор 10 исследований сна младенцев показал, что для 20-30\% всех младенцев характерны ночные пробуждения в течение первых двух лет жизни [35].

Нейрофизиологические исследования (ЭЭГ, сомнография) позволили выделить различные фазы сна; формирование этих фаз в онтогенезе подробно изучено [36]. В течение первого месяца ЭЭГ-картина сна ребенка представляет собой низкоамплитудную кривую с единичными "всплесками" медленных волн, и лишь в последующие 2-3 мес на ЭЭГ сна можно определить фазы медленного и быстрого движения глаз, которые чередуются в течение ночного сна [37]. Наиболее важной фазой считается сон с быстрыми движениями глаз - он сопровождается сновидениями, имеет значение в интеграции процессов памяти [38]. К возрасту $2-3$ мес у здорового ребенка обычно формируются традиционные циркадианные ритмы сна, после 6 мес ЭЭГ-паттерны быстрого и медленного сна приближаются к таковым взрослых [39] - доля быстрого (или глубокого) сна при этом снижается. В табл. 2 представлены рекомендации по продолжительности сна для детей до 5 лет; наряду с ними определены условные "нормативы" по частоте пробуждений длительностью более 5 мин во время сна (для детей 1-2 лет не более 2 раз за ночь; для более младших такие "нормы» не установлены) и по желательному времени засыпания (на первом году жизни это не более 30 мин) [31, 40].

У младенцев, достигших 1 года, существуют заметные различия по продолжительности сна в регионах и странах, обусловленные этико-культурными особенностями [42].

Расстройства сна детей первого года жизни нередко являются серьезной проблемой, создающей угрозу здоровью, ухудшающей качество жизни семьи. Хороший, спокойный сон рассматривается как один из показателей нормального физического, психомоторного, когнитивного развития ребенка. Дети, находящиеся на грудном вскармливании, чаще имеют здоровый сон, чем дети на искусственном вскармливании. Это свя-

Таблица 1. Диапазон средней продолжительности сна в сутки детей раннего возраста [31]

Table 1. Range of average sleep duration per day in infants [31]

\begin{tabular}{|l|c|c|c|}
\hline \multicolumn{1}{|c|}{ Возраст } & $\begin{array}{c}\text { Рекомендуемая } \\
\text { продолжительность сна / сутки, ч }\end{array}$ & $\begin{array}{c}\text { Допустимая } \\
\text { продолжительность, ч }\end{array}$ & $\begin{array}{c}\text { Нерекомендуемая } \\
\text { продолжительность сна / сутки, ч }\end{array}$ \\
\hline $\begin{array}{l}\text { Новорожденный } \\
\text {-3 мес }\end{array}$ & $14-17$ & $11-13$ & $>11$ \\
\hline $\begin{array}{l}\text { Младенцы } \\
\text { 4-11 мес }\end{array}$ & $12-15$ & $18-19$ & $>19$ \\
\hline $\begin{array}{l}\text { Дети младшего возраста } \\
1-2 \text { года }\end{array}$ & $11-14$ & $10-11$ & $>10$ \\
\hline
\end{tabular}


Таблица 2. Рекомендуемое количество и качество сна для детей в возрасте до 5 лет [31, 36, 41] Table 2. Recommended amount and quality of sleep for children under 5 years of age $[31,36,41]$

\begin{tabular}{|c|c|c|c|c|c|c|}
\hline \multirow{2}{*}{$\begin{array}{l}\text { Возрастная } \\
\text { категория }\end{array}$} & \multicolumn{3}{|c|}{ Продолжительность сна за 24 часа, ч } & \multicolumn{3}{|c|}{ Качество сна } \\
\hline & Рекомендуемая & Адекватная & Нерекомендуемая & $\begin{array}{c}\text { Задержка } \\
\text { сна* }^{*}\end{array}$ & $\begin{array}{c}\text { Пробуждения } \\
\text { (> } 5 \text { мин)** }\end{array}$ & $\begin{array}{c}\text { Эффективность } \\
\text { сна }^{\star \star *}\end{array}$ \\
\hline $\begin{array}{l}\text { Младенцы } \\
\text { (4-12 мес) }\end{array}$ & $12-15$ & $\begin{array}{l}10-11 \\
16-18\end{array}$ & $\begin{array}{l}<10 \\
>18\end{array}$ & $<30$ мин & Нет данных & $85 \%$ \\
\hline $\begin{array}{l}\text { Дети раннего возраста } \\
\text { (1-2 года) }\end{array}$ & $11-14$ & $\begin{array}{c}9-10 \\
15-16\end{array}$ & $\begin{array}{c}<9 \\
>16\end{array}$ & $<30$ мин & $\begin{array}{l}<2 \text { раз } \\
\text { за ночь }\end{array}$ & $85 \%$ \\
\hline $\begin{array}{l}\text { Дети дошкольного возраста } \\
\text { (3-5 лет) }\end{array}$ & $10-13$ & $\begin{array}{c}8-9 \\
14\end{array}$ & $\begin{array}{c}<8 \\
>14\end{array}$ & $<30$ мин & $\begin{array}{l}<2 \text { раз } \\
\text { за ночь }\end{array}$ & $85 \%$ \\
\hline
\end{tabular}

Примечание. <*> - задержка сна: время в минутах, необходимое для перехода от бодрствования ко сну; <**> - пробуждения (длительность > 5 мин): количество эпизодов за ночь, в которых ребенок бодрствует более 5 мин; <***> - эффективность сна: отношение общего количества сна к времени в кровати.

Note. $<*>$ - sleep delay: time to go from wakefulness to sleep in minutes; $<* *>-$ awakenings (duration $>5$ minutes): number of episodes per

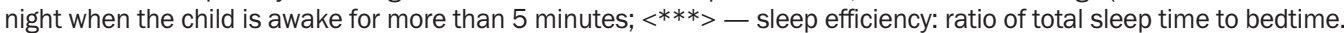

зано с циркадианными ритмами выработки триптофана грудного молока, предшественника регулятора сна мелатонина [43].

Для детей раннего возраста очень важны условия, в которых протекает сон, стереотипный порядок укладывания в безопасной и комфортной среде, обеспечение родителями успокаивающих и расслабляющих действий - теплая ванна, пение колыбельной песни, мягкое укачивание [44].

\section{ПРЯМАЯ И ОБРАТНАЯ СВЯЗЬ: КИШЕЧНАЯ МИКРОБИОТА И СОН}

От сосуществования к каузальности и от одной формы связи и взаимозависимости - к другой, более глубокой, более общей.

В.И. Ленин. Философские тетради

В настоящее время появились научные публикации, указывающие на связи разнообразия кишечного микробиома с характеристиками сна [45]. Это исследование было выполнено у взрослых мужчин, не имевших заболеваний желудочно-кишечного тракта; оценка качества сна проводилась методом актиграфии (фиксация характера сна и частоты пробуждений); осуществлялись психологическое тестирование, определение уровня цитокинов; ДНК-типирование штаммов микробиома. Были выявлены корреляции между всеми изученными параметрами; показатели интеллектуальных тестов достоверно зависели от разнообразия микробиома и эффективности сна (прямая корреляционная связь) и находились в отрицательной корреляционной связи с уровнем провоспалительного цитокина IL-6. В плане оценки характеристик микробиоты анализ определил положительную корреляцию между эффективностью сна и количеством, а также разнообразием видов Bacteroidetes. Выявлены корреляции между уровнем IL-6 и нарушениями абстрактного мышления по данным психологического тестирования. Похожие тенденции наблюдались при изучении количества, но не разнообразия в пределах филы Firmicutes. Таким образом, настоящее исследование обнаружило связи между физиологией сна и составом микробиома кишечника. Так, разнообразие микробиома положительно коррелировало (коэффициент корреляции $\rho=0,479, P=0,001$ ) с эффективностью сна и общим временем сна, а также отрицательно коррелировало ( $\rho=-0,853, P<0,001)$ с фрагментацией сна (WASO - Wake Time After Sleep Onset - время бодрствования после наступления сна). Эти результаты показывают, что разнообразие кишечного микробиома способствует более здоровому сну.

В экспериментальной работе было продемонстрировано, что хроническая фрагментация сна хотя и не связана с циркадианными сдвигами или недосыпанием, но заметно изменяет пищевое поведение и в конечном итоге способствует ожирению и инсулинорезистентности. Увеличение частоты приемов пищи, вызванное хронической фрагментацией сна, приводило к изменениям микробиоты кишечника с преимущественным ростом Lachnospiraceae и Ruminococcaceae и количественным уменьшением Lactobacillaceae. Эти изменения приводят к системному и висцеральному воспалению жировой ткани, изменению чувствительности к инсулину у мышей, вероятно, за счет повышения проницаемости слизистой оболочки толстой кишки [46].

Недавнее исследование среди взрослых людей показало, что хорошее качество сна связано с высокой долей бактерий фил Verrucomicrobia и Lentisphaerae в микробиоме кишечника и улучшением показателей при выполнении когнитивных задач [47].

В других исследованиях [48] ведущая роль в обеспечении качества сна отдается типам Bacteroidetes и Firmicutes; причем цитокиновый профиль - это «интерфейс" между микробиомом кишечника и характеристиками сна. Появляется все больше доказательств того, что представители этих типов могут модулировать циркадианный ритм [49] и потребление пищи [50], которые влияют на качество сна.

Некоторые бактериальные метаболиты определяются как механизм взаимодействия между кишечной микробиотой, иммунной системой и макроорганизмом через ось "мозг - кишечник - кишечная микробиота". Продуцируемые ферментирующими кишечными бактериями КЦЖК (бутират, ацетат и др.), взаимодействуя через данную ось, могут влиять на сон. Было выполнено исследование связи уровней фекальных КЦЖК у младенцев с характеристиками их сна [51]. Установлены таковые между уровнями ацетата, пропионата и бутирата в кале и продолжительностью сна. Наиболее отчетлива связь высокого уровня фекального пропионата с длительностью непрерывного сна. Такие КЦЖК, как бутират и ацетат, могут взаимодействовать с регуляторными клетками, подавлять провоспалительные цитокины и стимулировать 
выработку противовоспалительных цитокинов (напримep, IL-22) [52].

Кишечные бактерии родов Bacteroidetes [53], Actinobacteria и Firmicutes [54] продуцируют гамма-аминомасляную кислоту (ГАМК), нейромедиатор, который может проникать через гематоэнцефалический барьер [55] и обеспечивает хорошую продолжительность сна, малое количество пробуждений [56]. Имеются научные данные, что род Corynebacterium обладает метаболической способностью синтезировать серотонин, который является предшественником регулятора циркадианного ритма мелатонина [57].

Кишечная микробиота может стимулировать выработку цитокинов IL-6 и IL-1及, влияющих на дифференцировку регуляторных В-клеток [15]. Предполагается, что цитокины IL-1 $\beta$ и IL-6 связаны с физиологией сна $[58,59]$. Соматотропная гормональная и гипоталамо-гипофизарно-надпочечниковая системы частично опосредуют влияние цитокинов на сон [60].

Практически все цитированные выше исследования выполнены либо в эксперименте, либо с участием взрослых добровольцев; аналогичных исследований у детей почти не проводилось.

\section{ВОЗМОЖНЫЕ ПУТИ ДВУНАПРАВЛЕННОЙ КОРРЕКЦИИ НАРУШЕНИЙ В ТАНДЕМЕ "СОН - МИКРОБИОТА"}

Сон и бессонница, если то и другое бывает сверх меры, - болезнь.

Гиппократ

Грудное вскармливание имеет ведущее значение в онтогенезе кишечного микробиома младенца. Бактериальное разнообразие микробных сообществ кишечника ребенка первого года жизни и изменения его состава были связаны с долей ежедневного потребления грудного молока - даже после введения твердой пищи. При грудном вскармливании отмечаются более высокие пропорции бифидобактерий и Lactobacillus spp. в кишечной микробиоте [61].

Высказано предположение, что иногда дополнительные приемы пищи предлагаются младенцу для оптимизации процесса засыпания. Результаты недавнего исследования ( $n=715$ пар "мать - ребенок", 6-12 мес жизни) показали, что 78,6\% младенцев регулярно просыпались на протяжении ночного сна. Было выявлено, что младенцы, получавшие больше молока или продуктов прикорма в течение дня, реже кормились ночью [62]. Разработаны специальные программы для использования родителями младенцев, которые страдают частыми пробуждениями и медленно засыпают [63].

Отдельные исследования подтверждают концепцию "хронопитания", заключающуюся в возможности влияния диеты на ритм сна и бодрствования [64].

Возможным корректором организации здорового сна у детей раннего возраста, вероятно, являются продукты, содержащие диетические ингредиенты, которые оказывают благотворное влияние на физиологические функции организма, поддерживают и укрепляют здоровье, улучшают качество жизни. К таким функциональным компонентам пищи относятся пребиотики (scGOS/IcFOS, неперевариваемые пищевые волокна клетчатки) [65]. Пребиотики избирательно используются кишечными микроорганизмами, стимулируют рост и активность кишечных бактерий, устанавливая благоприятные симбиотические взаимоотношения со своим хозяином [43]. Обогащение рациона неперевариваемыми олигосахаридами дает возможность улучшить микробную экосистему кишечника, включая популяции бактерий, профили метаболитов, физиологические эффекты [62].

Экосистемный анализ влияния диетического вмешательства с использованием пребиотических фруктанов инулиноподобного типа на микробиоту толстой кишки показал, что этот эффект специфически связан с изменениями в относительных содержаниях Anaerostipes, Bilophila и Bifidobacterium [66].

Необходима дальнейшая разработка программ комплексного семейного сопровождения младенцев с нарушениями сна, что позволит одновременно корригировать поведенческие и когнитивные нарушения у них [22]; однако комплексные подходы в создании таких программ с включением таргетной коррекции микробиома у детей пока остаются неразработанными.

\section{ЗАКЛЮЧЕНИЕ}

Целенаправленная регуляция количественного и качественного состава кишечной микробиоты, профиля метаболитов кишечных бактерий с помощью направленного изменения состава продуктов детского питания может способствовать формированию здорового сна у младенца через ось "мозг - кишечник - микробиота". Использование целенаправленной коррекции состава кишечной микробиоты в научно обоснованных программах раннего вмешательства наряду с рекомендациями по организации сна ребенка будут способствовать гармоничному развитию детей.

\section{ИСТОЧНИК ФИНАНСИРОВАНИЯ}

Статья опубликована при поддержке компании АО «ПРОГРЕСС".

\section{FINANCING SOURCE}

The article was funded by "Progress".

\section{РАСКРЫТИЕ ИНТЕРЕСОВ}

И.А. Беляева - чтение лекций для компании АО "ПРОГРЕСС", «МЕДЕЛА», «АКРИХИН", «НЕСТЛЕ", «ХИПП".

Т.В. Турти - чтение лекций для компании АО «ПРОГРЕСС", "АКРИХИН".

Остальные авторы статьи подтвердили отсутствие конфликта интересов, о котором необходимо сообщить.

\section{DISCLOSURE OF INTEREST}

Irina A. Belyaeva - lecturing for pharmaceutical companies “Progress”, “Medela”, “Akrikhin”, Nestle, “HiPP Russ” LLC.

Tatiana V. Turti - lecturing for pharmaceutical companies "Progress", “Akrikhin".

The other contributors confirmed the absence of a reportable conflict of interests.

\section{ORCID}

И.А. Беляева

https://orcid.org/0000-0002-8717-2539

Т.В. Турти

https://orcid.org/0000-0002-4955-0121

Е.П. Бомбардирова

https://orcid.org/0000-0002-6677-2914

П.Е. Садчиков

https://orcid.org/0000-0001-9225-8372 


\section{СПИСОК ЛИТЕРАТУРЫ / REFERENCES}

1. Stiemsma LT, Michels KB. The role of the microbiome in the developmental origins of health and disease. Pediatrics. 2018;141(4):e20172437. doi: 10.1542/peds.2017-2437

2. Underwood MA, Mukhopadhyay S, Lakshminrusimha S, et al. Neonatal intestinal dysbiosis. J Perinatol. 2020;40(11):1597-1608. doi: 10.1038/s41372-020-00829-2

3. Walker RW, Clemente JC, Peter I, Loos RJF. The prenatal gut microbiome: are we colonized with bacteria in utero? Pediatr Obes. 2017;12(1):3-17. doi: 10.1111/ijpo.12217

4. Nagpal R, Tsuji H, Takahashi T, et al. Sensitive Quantitative Analysis of the Meconium Bacterial Microbiota in Healthy Term Infants Born Vaginally or by Cesarean Section. Front Microbiol. 2016;7:1997. doi: 10.3389/fmicb.2016.01997

5. Nagpal R, Tsuji H, Takahashi T, et al. Ontogenesis of the Gut Microbiota Composition in Healthy, Full-Term, Vaginally Born and Breast-Fed Infants over the First 3 Years of Life: A Quantitative Bird's-Eye View. Front Microbiol. 2017;8:1388. doi: 10.3389/ fmicb.2017.01388

6. Lyons KE, Ryan CA, Dempsey EM, et al. Breast Milk, a Source of Beneficial Microbes and Associated Benefits for Infant Health. Nutrients. 2020;12(4):1039. doi: 10.3390/nu12041039

7. Fujimura KE, Sitarik AR, Havstad S, et al. Neonatal gut microbiota associates with childhood multisensitized atopy and T cell differentiation. Nat Med. 2016;22(10):1187-1191. doi: 10.1038/nm.4176

8. Zheng D, Liwinski T, Elinav E. Interaction between microbiota and immunity in health and disease. Cell Res. 2020;30(6): 492-506. doi: 10.1038/s41422-020-0332-7

9. Carabotti M, Scirocco A, Maselli MA, et al. The gut-brain axis: interactions between enteric microbiota, central and enteric nervous systems. Ann Gastroenterol. 2015;28(2):203.

10. Ley RE, Peterson DA, Gordon Jl. Ecological and evolutionary forces shaping microbial diversity in the human intestine. Cell. 2006;124(4):837 -848. doi: 10.1016/j.cell.2006.02.017

11. Mayer EA, Tillisch K, Gupta A. Gut/brain axis and the microbiota. J Clin Invest. 2015;125(3):926-938. doi: 10.1172/JCI76304

12. Feitong L, Jie L, Fan W, et al. Altered composition and function of intestinal microbiota in autism spectrum disorders: a systematic review. Trans/ Psychiatry. 2019;9(1):43. doi: 10.1038/ s41398-019-0389-6

13. Belkaid Y, Hand TW. Role of the microbiota in immunity and inflammation. Cell. 2014;157(1):121-141. doi: 10.1016/ j.cell.2014.03.011

14. Zelante T, lannitti RG, Cunha C, et al. Tryptophan catabolites from microbiota engage aryl hydrocarbon receptor and balance mucosal reactivity via interleukin-22. Immunity. 2013;39(2): 372-385. doi: 10.1016/j.immuni.2013.08.003

15. Rosser EC, Oleinika K, Tonon S, et al. Regulatory B cells are induced by gut microbiota-driven interleukin-1 $\beta$ and interleukin- 6 production. Nat Med. 2014;20(11):1334. doi: org/10.1038/ $\mathrm{nm} .3680$

16. Brett BE, de Weerth $C$. The microbiota-gut-brain axis: A promising avenue to foster healthy developmental outcomes. Dev Psychobiol. 2019;61(5):772-782. doi: 10.1002/dev.21824

17. Zhu X, Han Y, Du J, et al. Microbiota-gut-brain axis and the central nervous system. Oncotarget. 2017;8(32):53829-5338. doi: 10.18632/oncotarget.17754

18. Cani PD, Knauf C. How gut microbes talk to organs: The role of endocrine and nervous routes. Mol Metab. 2016;5(9):743-752. doi: 10.1016/j.molmet.2016.05.011

19. Cani PD, Possemiers S, Van de Wiele T, et al. Changes in gut microbiota control inflammation in obese mice through a mechanism involving GLP-2-driven improvement of gut permeability. Gut. 2009;58(8):1091-1103. doi: 10.1136/gut.2008.165886

20. Braniste V, Al-Asmakh M, Kowal C, et al. The gut microbiota influences blood-brain barrier permeability in mice. Sci Trans Med. 2014;6(263):263ra158-263ra158. doi: 10.1126/ scitranslmed.3009759

21. Gobin CM, Banks JB, Fins Al, et al. Poor sleep quality is associated with a negative cognitive bias and decreased sustained attention. J Sleep Res. 2015;24(5):535-542. doi: 10.1111/jsr.12302

22. Sun W, Li SX, Jiang Y, et al. A community-based study of sleep and cognitive development in infants and toddlers. J Clin Sleep Med. 2018;14(6):977-984 doi: 10.5664/jcsm.7164
23. Super CM, Blom MJM, Harkness S, et al. Culture and the organization of infant sleep: A study in the Netherlands and the U.S.A. Infant Behav Dev. 2021;64:101620. doi: 10.1016/ j.infbeh.2021.101620

24. Öztürk M, Boran P, Ersu R, Peker Y. Possums-based parental education for infant sleep: cued care resulting in sustained breastfeeding. Eur J Pediatr. 2021;180(6):1769-1776. doi: 10.1007/s00431-021-03942-2

25. Besedovsky L, Lange T, Haack M. The sleep-immune crosstalk in health and disease. Physiol Rev. 2019;99(3):1325-1380. doi: 10.1152/physrev.00010.2018

26. Mindell JA, Leichman ES, Composto J, et al. Development of infant and toddler sleep patterns: real-world data from a mobile application. J Sleep Res. 2016;25(5):508-516. doi: 10.1111/ jsr.12414

27. Byars KC, Yolton K, Rausch J, et al. Prevalence, patterns, and persistence of sleep problems in the first 3 years of life. Pediatrics. 2012;129(2):e276-e284. doi: 10.1542/peds.2011-0372

28. Bruni O, Baumgartner E, Sette S, et al. Longitudinal study of sleep behavior in normal infants during the first year of life. J Clin Sleep Med. 2014;10(10):1119-1127. doi: 10.5664/jcsm.4114 29. Pacheco D. Babies and Sleep. In: Sleep Foundation. Available online: https://www.sleepfoundation.org/baby-sleep. Accessed on December 2, 2021.

30. Henderson JM, France KG, Owens JL, et al. Sleeping through the night: the consolidation of self-regulated sleep across the first year of life. Pediatrics. 2010 infants' nocturnal sleep across the first year of life. Sleep Med Rev. 2011;15(4):211-220. doi: 10.1016/ j.smrv.2010.08.003

31. Hirshkowitz M, Whiton K, Albert SM, et al. National Sleep Foundation's updated sleep duration recommendations: final report. Sleep Health. 2015;1(4):233-243. doi: 10.1016/ j.sleh.2015.10.004

32. Shepard-Ohta R. Consolidated Sleep for Infants: Is it Necessary to Healthy Brain Development? Hey Sleepy Baby, LLC; 2021 May 27. Available online: https://heysleepybaby.com/blog/consolidatedsleep-for-infants-is-it-necessary-to-healthy-brain-development. Accessed on December 2, 2021.

33. Walker M. Why We Sleep: Unlocking the Power of Sleep and Dreams. New York, NY: Scribner; 2017. 359 p.

34. Pennestri MH, Laganière $C$, Bouvette-Turcot $A A$, et al. Uninterrupted Infant Sleep, Development, and Maternal Mood. Pediatrics. 2018;142(6):e20174330. doi: 10.1542/ peds.2017-4330

35. Tham EK, Schneider N, Broekman BF. Infant sleep and its relation with cognition and growth: a narrative review. Nat Sci Sleep. 2017;9:135-149. doi: 10.2147/NSS.S125992

36. Jiang F. Sleep and Early Brain Development. Ann Nutr Metab. 2019;75:(1):44-54. doi: 10.1159/000508055

37. Roffwarg HP, Muzio JN, Dement WC. Ontogenetic development of the human sleep-dream cycle. Science. 1966;152(3722):604-619. doi: $10.1126 /$ science.152.3722.604

38. Kryger MH, Roth T, Dement WC. Principle and practice of sleep medicine. 5th ed. Philadelphia: Saunders/Elsevier; 2011.

39. Sheldon SH, Sateia MJ, Carskadon MA. Sleep in infants and children. In: Sleep Medicine. Lee-Chiong TL, Sateia MJ, Carskadon MA, eds. Philadelphia (PA): Hanley and Belfus Inc; 2002. pp. 99-103.

40. Chaput JP, Dutil C, Sampasa-Kanyinga H. Sleeping hours: what is the ideal number and how does age impact this? Nat Sci Sleep. 2018;10:421-430. doi: 10.2147/NSS.S163071

41. Hirshkowitz M, Whiton K, Albert SM, et al. National Sleep Foundation's sleep time duration recommendations: methodology and results summary. Sleep Health. 2015;1(1):40-43. doi: 10.1016/j.sleh.2014.12.010

42. Lin QM, Spruyt K, Leng Y, et al. Cross-cultural disparities of subjective sleep parameters and their age-related trends over the first three years of human life: A systematic review and meta-analysis. Sleep Med Rev. 2019;48:101203. doi: 10.1016/ j.smrv.2019.07.006

43. Cubero J, Valero V, Sánchez J, et al. The circadian rhythm of tryptophan in breast milk affects the rhythms of 6-sulfatoxymelatonin and sleep in newborn. Neuro Endocrinol Lett. 2005; 26(6):657-661. 
44. Hagan JF, Shaw JS, Duncan PM. Bright Futures: Guidelines for Health Supervision of Infants, Children, and Adolescents. Elk Grove Village (IL): American Academy of Pediatrics; 2008.

45. Smith RP, Lyle SM, et al. Gut microbiome diversity is associated with sleep physiology in humans. PLoS One. 2019;14(10):e0222394. doi: 10.1371/journal.pone.0222394

46. Poroyko VA, Carreras A, Khalyfa A, et al. Chronic sleep disruption alters gut microbiota, induces systemic and adipose tissue inflammation and insulin resistance in mice. Sci Rep. 2016;6:35405. doi: $10.1038 /$ srep35405

47. Anderson JR, Carroll I, Azcarate-Peril MA, et al. A preliminary examination of gut microbiota, sleep, and cognitive flexibility in healthy older adults. Sleep Med. 2017;38:104-107. doi: 10.1016/ j.sleep.2017.07.018

48. Smith RP, Easson C, Lyle SM, et al. Gut microbiome diversity is associated with sleep physiology in humans. PLoS One. 2019; 14(10):e0222394. doi: 10.1371/journal. pone.0222394

49. Parkar SG, Kalsbeek A, Cheeseman JF. Potential Role for the Gut Microbiota in Modulating Host Circadian Rhythms and Metabolic Health. Microorganisms. 2019;7(2):41. doi: 10.3390/ microorganisms7020041

50. Singh RK, Chang H-W, Yan D, et al. Influence of diet on the gut microbiome and implications for human health. J Transl Med. 2017;15(1):73 doi: 10.1186/s12967-017-1175-y

51. Heath A-LM, Haszard JJ, Galland BC, et al. Association between the faecal short-chain fatty acid propionate and infant sleep. Eur J Clin Nutr. 2020;74(9):1362-1365. doi: 10.1038/s41430-019-0556-0 52. Smith PM, Howitt MR, Panikov N, et al. The microbial metabolites, short-chain fatty acids, regulate colonic Treg cell homeostasis. Science. 2013;341(6145):569-573. doi: 10.1126/ science.1241165

53. Strandwitz P, Kim KH, Terekhova D, et al. GABA-modulating bacteria of the human gut microbiota. Nat Microbiol. 2019;4(3):396 doi: 10.1038/s41564-018-0307-3

54. Yunes R, Poluektova E, Dyachkova M, et al. GABA production and structure of gadB/gadC genes in Lactobacillus and Bifidobacterium strains from human microbiota. Anaerobe. 2016;42:197-204. doi: 10.1016/j.anaerobe.2016.10.011

55. Todd N, Zhang Y, Power Ch, et al.Modulation of brain function by targeted delivery of GABA through the disrupted blood-brain barrier. Neiroimage. 2019;189:267-275. doi: 10.1016/j.neuroimage.2019.01.037
56. Gottesmann C. GABA mechanisms and sleep. Neuroscience. 2002;111(2):231-239. doi: 10.1016/s0306-4522(02)00034-9 57. Ursin R. Serotonin and sleep. Sleep Med Rev. 2002;6(1):55-67. doi: 10.1053/smrv.2001.0174

58. Frey DJ, Fleshner M, Wright KP Jr. The effects of 40 hours of total sleep deprivation on inflammatory markers in healthy young adults. Brain Behav Immun. 2007;21(8):1050-1057. doi: 10.1016/ j.bbi.2007.04.003

59. Miller AH, Maletic V, Raison CL. Inflammation and its discontents: the role of cytokines in the pathophysiology of major depression. Biol Psychiatry. 2009;65(9):732-741. doi: 10.1016/ j.biopsych.2008.11.02

60. Nicolaides NC, Vgontzas AN, Kritikou I, et al. HPA Axis and Sleep. [Updated 2020 Nov 24]. In: Endotext [Internet]. Feingold KR, Anawalt B, Boyce A, et al., eds. South Dartmouth (MA): MDText.com, Inc.; 2000. Available online: https://www.ncbi.nlm.nih.gov/books/ NBK279071. Accessed on December 4, 2021.

61. Pannaraj PS, Li F, Cerini C, et al. Association between breast milk bacterial communities and establishment and development of the infant gut microbiome. JAMA Pediatr. 2017;171(7): 647-654. doi: 10.1001/jamapediatrics.2017.0378

62. Brown A, Harries V. Infant sleep and night feeding patterns during later infancy: association with breastfeeding frequency, daytime complementary food intake, and infant weight. Breastfeed Med. 2015;10(5):246-252. doi: 10.1089/bfm.2014.0153

63. Ball HL, Taylor CE, Thomas V, Douglas PS. Development and evaluation of 'Sleep, Baby \& You' - An approach to supporting parental well-being and responsive infant caregiving. PLoS One. 2020;15(8):e0237240. doi: 10.1371/journal.pone.0237240

64. Cubero J, Chanclón B, Sánchez S, et al. Improving the quality of infant sleep through the inclusion at supper of cereals enriched with tryptophan, adenosine-5'-phosphate, and uridine-5'phosphate. Nutr Neurosci. 2009;12(6):272-280. doi: 10.1179/ $147683009 \times 423490$

65. Krol KM, Grossmann T. Psychological effects of breastfeeding on children and mothers. Bundesgesundheitsblatt Gesundheitsforschung Gesundheitsschutz. 2018;61(8):977-985. doi: $10.1007 /$ s00103-018-2769-0

66. Vandeputte D, Falony G, Vieira-Silva S, et al. Prebiotic inulin-type fructans induce specific changes in the human gut microbiota. Gut. 2017;66(11):1968-1974. doi: 10.1136/gutjnl-2016-313271

\title{
ПИЩЕВАЯ АЛЛЕРГИЯ У ДЕТЕЙ. МЕТОДИЧЕСКОЕ РУКОВОДСТВО
}

\author{
Авторы: Баранов А.А., Намазова-Баранова Л.С.,
} Хаитов Р.М. и др.

М.: Педиатръ, 2021. - 76 с.

$\mathrm{B}$ издании представлены современные сведения об эпидемиологии, этиологии и клинических проявлениях аллергических реакций на продукты питания у детей. Освещены основанные на доказательной медицине подходы к диагностике, в том числе, дифференциальной, лечению и профилактике пищевой аллергии у детей. Подробно изложены тактика и алгоритмы ведения пациентов. Методическое руководство предназначено для врачей-педиатров, врачей общей практики (семейных врачей), врачей-аллергологов-иммунологов, врачей-гастроэнтерологов и врачей-диетологов, а также студентов старших курсов медицинских вузов и обучающихся в ординатуре, аспирантуре.

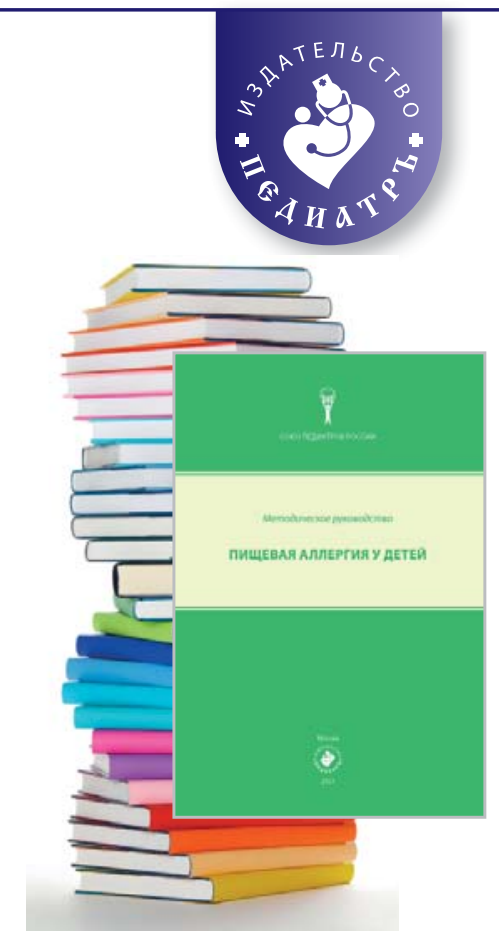

